\title{
Assessment of Seismic behavior of a RC Precast building
}

\author{
Hugo Vitorino ${ }^{1}$, Nadia Batalha ${ }^{2}$, Romain Sousa ${ }^{1}$, Paulo Fernandes ${ }^{3}$, Humberto \\ Varum $^{2}$, Hugo Rodrigues ${ }^{4 *}$ \\ ${ }^{1}$ ESTG- Polytechnic Institute of Leiria, Leiria, Portugal \\ ${ }^{2}$ CONSTRUCT-LESE, Faculty of Engineering (FEUP), University of Porto, Porto, Portugal \\ ${ }^{3}$ CERIS, ESTG- Polytechnic Institute of Leiria, Leiria, Portugal \\ ${ }^{3}$ RISCO-, ESTG- Polytechnic Institute of Leiria, Leiria, Portugal \\ *corresponding author: hugo.f.rodrigues@ipleiria.pt
}

\begin{abstract}
Past earthquakes brought attention to the poor performance of precast reinforced concrete structures. One of the problems observed in those structures is related to the beam-to-column connections. The evaluation of different methodologies for the analysis of beam-to-column connections in industrial buildings is an important aspect that should be studied. The numerical analyses developed allowed the study of the effect that different connection properties have on the frequencies of vibration, members drifts and seismic coefficients. The connection properties were modelled through a macro-element that considers the friction (between concrete-concrete and concrete-neoprene) and the steel dowels. The results showed that the friction between concrete elements and the consideration of the neoprene in the connection have a small impact on the drifts demands in the columns and seismic coefficient of the analyzed structure; on the other hand, the effect of the steel dowel on the drift demand and seismic coefficient is significant. The comparison of the models with different properties and connections allowed a better understanding of the factors with a higher impact on the results.
\end{abstract}

Keywords: Industrial Buildings, Precast Reinforced Concrete, Beam-to-Column Connections, Seismic Performance, Numerical Analysis.

\section{Introduction}

Precast reinforced concrete $(\mathrm{RC})$ structures have shown in several cases a poor seismic performance presenting damages on structural and non-structural elements, highlighting the vulnerability of industrial buildings [1]-[4]. An important part of these buildings was not designed with seismic provisions. Most of the observed damages are related to structural elements, namely in the beam-to-column connections. In several buildings were observed significant failures and collapses. For example, after the 2011 earthquake in Emilia Romagna, more than half of the existing precast structures exhibited significant damages [5]. Even in moderate and short duration earthquakes events, RC structures exhibit high levels of structural damages as Romão et al. described after field observations of the 2011 Lorca earthquake [6]. The unceasing reports of damages on precast structures derived from seismic events pointed to a need for consistent 
methodologies for analysis, modeling and assessment of existing constructions. Those models need to account for the interaction between structural elements (e.g. beam-tocolumns connections) and structural and non-structural elements in order to describe the non-linear dynamic behavior of this type of structures [7]. In the precast topic, Sacks et al. [8] presented a parametric work with 3D modeling with examples from precast concrete, analyzing the requirements, features and performance of a CAD platform. The need to assess the seismic vulnerability of existing buildings led different authors to develop new modeling solutions following both macro (e.g., [9]-[12]) and refined numerical models (e.g., [13]-[15]). The use of refined models tends to offer more precise results given the ability to consider the different mechanisms involved. However, these models are computationally demanding and, therefore, unsuitable for common engineering applications or seismic risk analyses at a large building scale. Since the beam-to-column connections were identified as one of the most critical elements in precast structures under seismic loads, some works were developed in this field in the last years. It should be highlighted the works of Casotto et al. [11] and Magliulo et al. [12] that are focused on the behavior connections without dowels, others, e.g. Clementi et al. [9], account only for the contribution of the dowels. The macro-element adopted in the present work follows the model proposed by Sousa et al. [16], which explicitly simulate the contribution of both friction and dowel action.

\section{Parametric Study}

\subsection{Description of the Case Study}

The RC precast building under study represents an industrial framed structure (Fig. 1.) constituted by one floor with an area of $180 \times 175 \mathrm{~m}^{2}$ and a height of $12 \mathrm{~m}$. The structure has 5 spans in the $\mathrm{X}$ direction (Fig. 2.) with $35 \mathrm{~m}$ of length each and 15 spans in the $\mathrm{Y}$ direction with $12 \mathrm{~m}$ of length each. The columns of the structure have a height of $12 \mathrm{~m}$ (the height of the building) and a rectangular section of $0,70 \times 0,50 \mathrm{~m}$ (Error! Reference source not found. 3 .) with a $40 \mathrm{~mm}$ cover. The concrete used was the $\mathrm{C} 40 / 50$ and the steel was the S500 NR-SD. The beams are pre-stressed with an I variable section, with a length of $35 \mathrm{~m}$ and a $30 \mathrm{~mm}$ cover. The columns are assumed fix to the foundation. In Europe, the most common type of beam-to-column connection in precast RC industrial buildings is the dowel beam-to-column connection [17]. In this system, the beam is mechanically connected to the column through vertical steel dowels. These dowels, usually one or two, protruding from the column's corbel, fit into sleeves left in the edge of the beams, which are later filled with a proper grout. In several cases, a steel or neoprene pad is placed between the column and the beam. These connections do not restrain the rotations between both members, while the transfer of horizontal forces between the beam and column is essentially ensured by friction and dowels (if present). In this type of connection, the transfer of the horizontal forces between the beams and columns is essentially ensured by the dowel action and friction between the beam and column [18]. 


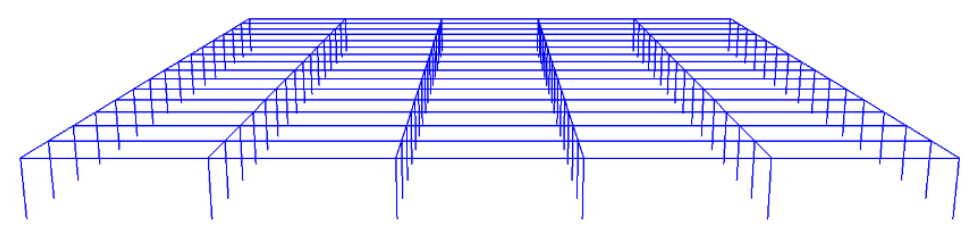

79

81

82

83

84

85

86

87

88

89

90

91

92

93

94

95

96

97

100

101

Fig. 1. A 3D overview of the building under study.

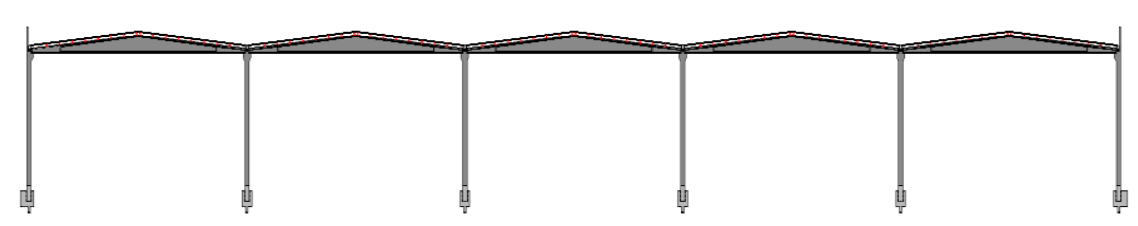

Fig. 2. Principal direction $(\mathrm{X})$ of the framed structure.

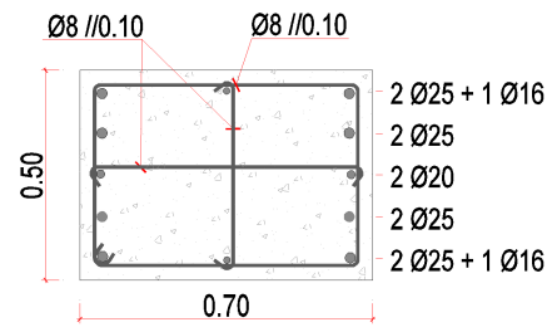

Fig. 3. Column section.

For the numerical analysis, constant vertical loads distributed on beams were considered to simulate the dead load of the self-weight of roof and RC elements, and the corresponding quasi-permanent value of live loads, giving a total value of $0.65 \mathrm{kN} / \mathrm{m}^{2}$. The 3D models were subjected to incremental dynamic analysis (IDA). A total of 10 ground motion record were selected from real previous seismic events according to the Araújo et al. [19] method. The average of the earthquake records fit the Eurocode 8 spectrum according to Type 1, for Lisbon, soil type A and were progressively scaled.

\subsection{Sensitivity Parameters}

To understand the seismic performance of the structure a parametric study was developed. Several cases were considered in a 3D model to better understand the impact that certain parameters have on the response of the building. The parameters considered are focused on the response of the beam-to-column connections, namely regarding the relative importance of the contribution of the dowels, neoprene and friction. Each case was named according to the properties considered in the model, for example, the case DFNC corresponds to a Dowel, Friction and Neoprene Connection considered in the 
102 model, in the same way, the case DC corresponds to a Dowel Connection and the case 103 FNC corresponds to a Friction and Neoprene Connection considered in the model. The 104 model PC corresponds to Pinned Connections considered in the model. In Table 1 is 105 the list of properties adopted in the different models.

106

Table 1. List of properties adopted in the different models.

\begin{tabular}{|c|c|c|c|c|}
\hline \multirow{2}{*}{ Model } & \multicolumn{2}{|c|}{ Number/Diameter of Dowels [mm] } & \multirow{2}{*}{ Friction } & \multirow{2}{*}{ Neoprene Pad [mm } \\
\hline & X Dir. & Y Dir. & & \\
\hline $\mathrm{PC}$ & \multicolumn{4}{|c|}{ Pinned Connection } \\
\hline DFNC & $2 ø 24$ & $2 ø 20$ & Yes & 20 \\
\hline DC & $2 \varnothing 24$ & $2 \varnothing 20$ & $\mathrm{NC}$ & $\mathrm{NC}$ \\
\hline $\mathrm{FNC}$ & $\mathrm{NC}$ & $\mathrm{NC}$ & Yes & 20 \\
\hline
\end{tabular}

107

NC- not considered in the model

\section{$108 \quad 3 \quad$ Results}

\section{$109 \quad 3.1 \quad$ Contribution of the Connection to the global behavior}

110 One of the main aims of the present study is to assess the effects of the connection in 111 the global behavior of the building under study. In Table 2 are presented the $1^{\text {st }}$ and $2^{\text {nd }}$ 112 frequency of the different structures with different connections. The models with 113 pinned connections (PC) and DFNC connections have the same frequencies. This situ114 ation shows that, for this model, when analyzing the frequencies, considering a detailed 115 connection with dowel, neoprene and friction is the same as considering a pinned con116 nection. The models with DFNC and DC connections have the same frequencies, which 117 shows the very low impact of the neoprene and friction on the structure frequency. On 118 the other hand, the models with DFNC and FNC connections have different contribu119 tions to the global stiffness of the structure, which shows that the dowels may have a 120 significant impact on structure behavior in terms of strength, as expected, but also in 121 the global stiffness.

Table 2. Frequency comparison between the models with different connections.

\begin{tabular}{ccc}
\hline Model & Frequency $1(\mathrm{~Hz})$ & Frequency 2 $(\mathrm{Hz})$ \\
\hline PC & 0.44 & 0.65 \\
DFNC & 0.44 & 0.65 \\
DC & 0.44 & 0.65 \\
FNC & 0.44 & 0.48 \\
\hline
\end{tabular}

\subsection{DFNC connection and Pinned connection}

126 In the present section, the DFNC model is compared with the PC model to find the 127 difference between considering a model with a connection with dowel, friction and ne128 oprene and a model with pinned connections, usually considered in the common design 


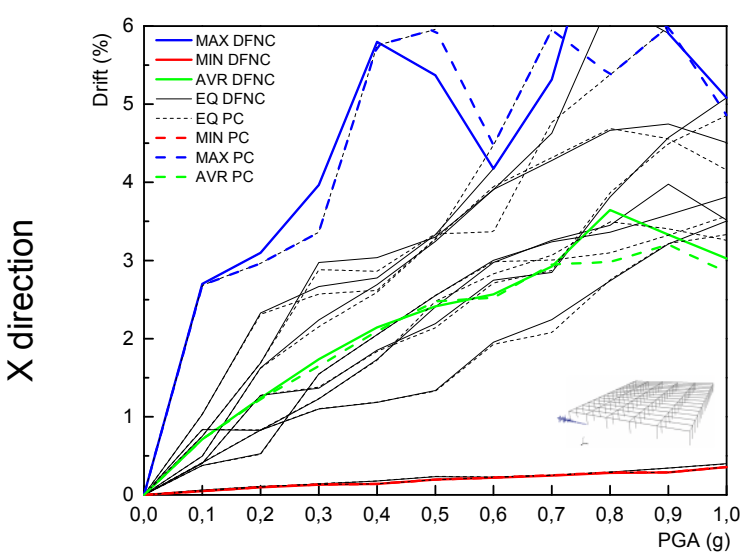

a) Drift comparison the PC model.

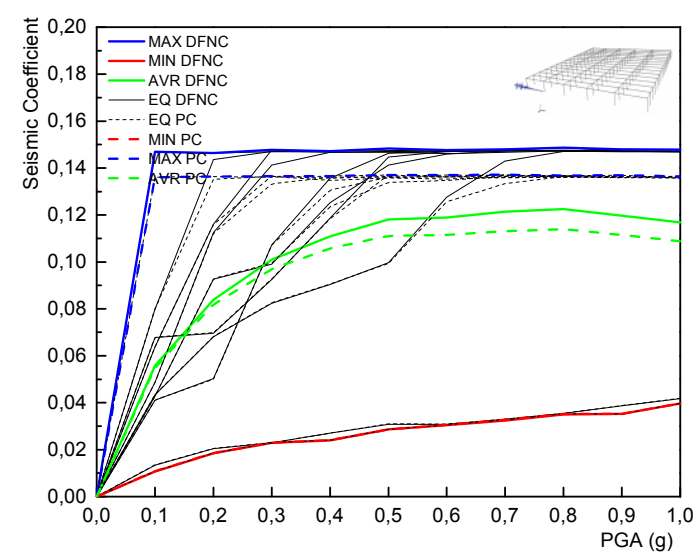

b) Seismic coefficient comparison

stage. In Figure 4 are represented the drifts and seismic coefficients for the DFNC and $\mathrm{PC}$ models in the X direction. The difference between the DFNC and PC models is very low, which shows that developing a connection model with dowels, friction and neoprene might not be necessary to study the drifts and seismic coefficients of the structure. Considering a pinned connection leads to a relatively simpler model that has practically the same results as considering a model with dowel, friction and neoprene connections. Most of the time, the DFNC model leads to slightly higher results when compared with

Fig. 4. Model with pinned and DFNC connections.

\subsection{Effect of the neoprene and friction}

In the present section is discussed the comparisons of the drift and seismic coefficient with DC and DFNC connections, to evaluate the effect of the connection only with the dowel and the connection considering the dowel, friction and neoprene. For the building under study this effect seems to not play a significant role. Figure 5 shows that the difference between considering a DC and DFNC connection is inexistent, leading to a low influence of the friction and neoprene in the drift and seismic coefficient of the structure. In fact, in other studies [16], only focused in the connection level, the contribution of the friction and neoprene are evaluated around $25 \%$ of the global connection response. Both cases can be true, once in the building under study the connection does not experience a huge demand, like observed in the previous studies. For buildings with higher demands at the connection level, the contribution of the friction and neoprene pad may not be so insignificant. 


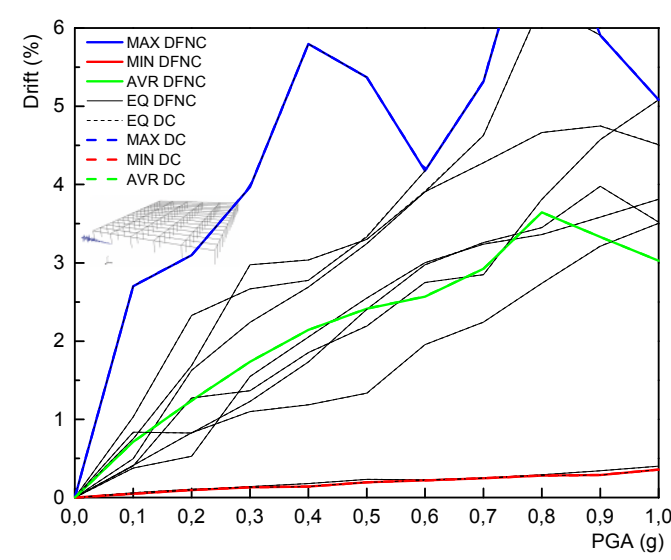

a) Drift comparison

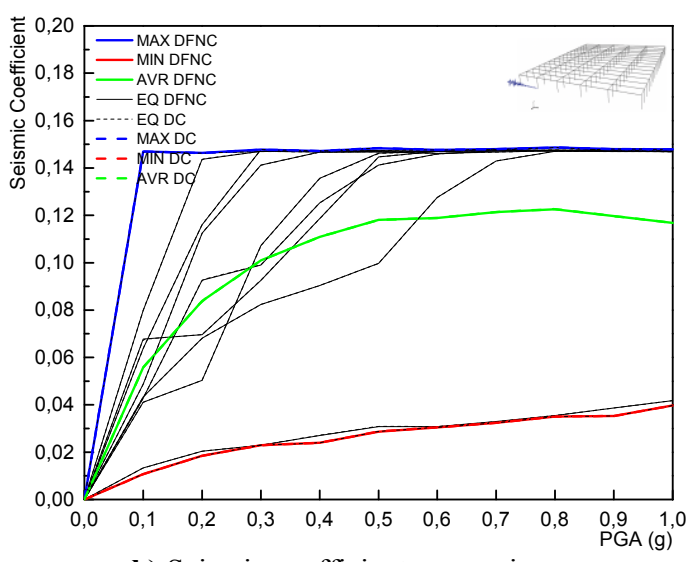

b) Seismic coefficient comparison

Fig. 5. Model with DC and DFNC connections.

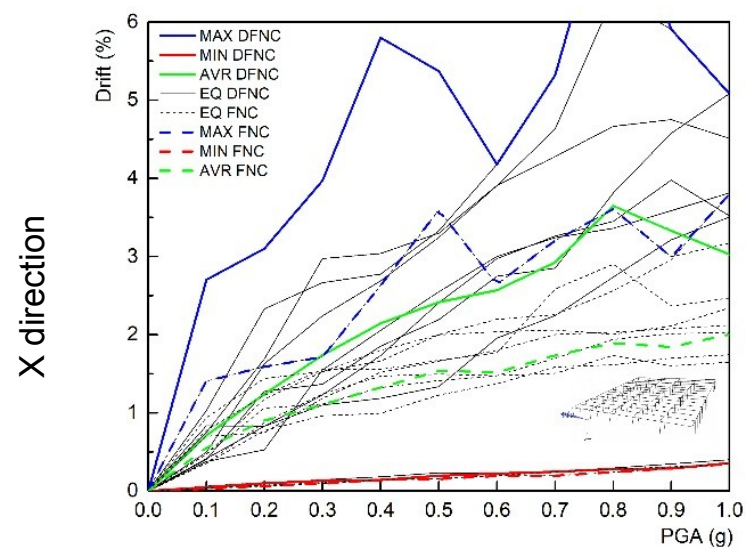

a) Drift comparison

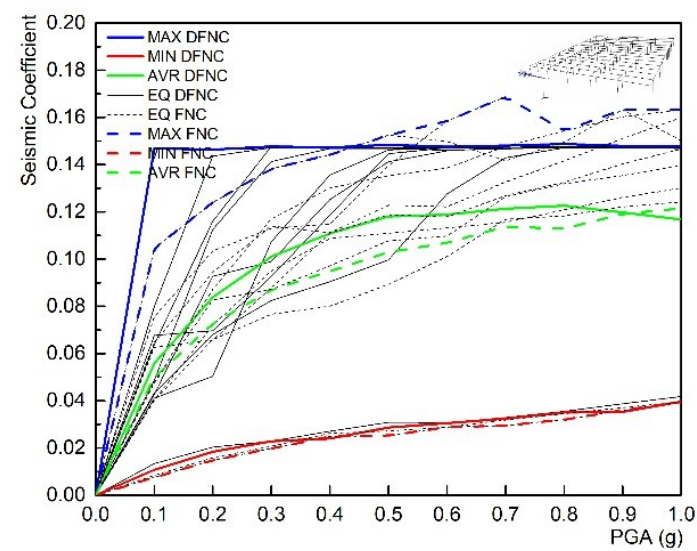

b) Seismic coefficient comparison

Fig. 6. Model with DFNC and FNC connections. 
1654 Concluding Remarks

166 Several comparisons between models featuring different beam-to-column connections

167 were developed to assess its contribution and impact to the global behavior of general

168 RC precast structures. The comparison between the models DFNC and PC showed that

169 the models have the same frequencies and equivalent results of the drift and the seismic

170 coefficient. This situation shows that considering a detailed connection with dowels,

171 neoprene and friction may not be necessary to study the drifts and seismic coefficients

172 of the structure. Comparing the models DFNC and DC allows the evaluation of the

173 effect of the neoprene and friction on the structure. The frequencies of the models

174 DFNC and DC are the same. The drift and seismic coefficient in the X direction of the

175 DFNC and DC models are similar which shows that there is no contribution of the 176 neoprene and friction on the drift and seismic coefficient of the structure. The compar177 ison between the models DFNC and FNC allowed the evaluation of the effect of the 178 dowels on the structure. The dowels, contrary to the friction and neoprene, have a sig179 nificant impact on the drift and seismic coefficient of the structure. For the same PGA, 180 the FNC model has lower drift demand when compared with the DFNC model. For 181 lower PGA, the seismic coefficient in the model FNC is lower than in the model DFNC. 182 For higher PGA, it is the contrary, the seismic coefficient in the model FNC is higher 183 than in the model DFNC. From a general point of view, the results showed the im184 portance of the beam-to-column connections to the seismic behavior of the entire struc185 ture. In the presence of adequately design dowels, small deformations are expected at 186 the connections level and, therefore, the response of the structures is controlled by the 187 properties of the vertical elements. For these cases, the consideration of simple pinned 188 connection appears as an efficient and accurate numerical approach. On the other hand, 189 in the absence of dowels, or in cases where these are not properly designed, a concen190 tration of damage is expected to occur at the connection level, whilst the columns re191 mains essentially undeformed. Hence, whenever the relative horizontal strength be192 tween the columns and the adjacent connections is unknown, the consideration of the 193 different connection mechanisms is recommended in order to obtain a reliable estima194 tion of the seismic behavior of the building.

195

196

\section{ACKNOWLEDGMENTS}

This work was financially supported by Project POCI-01-0145-FEDER-028439 "SeismisPRECAST Seismic performance ASSessment of existing Precast Industrial buildings and development of Innovative Retrofitting sustainable solutions" funded by FEDER funds through COMPETE2020 - Programa Operacional Competitividade e Internacionalização (POCI) and by national funds (PIDDAC) through FCT/MCTES. The second author acknowledged to FCT - Fundação para a Ciência e a Tecnologia namely through the PhD grant with reference SFRH/BD/139723/2018.

\section{References}

[1] A. Belleri, E. Brunesi, R. Nascimbene, M. Pagani, and P. Riva, "Seismic performance of precast industrial facilities following major earthquakes in the Italian territory," $J$. Perform. Constr. Facil., pp. 1-31, 2014. 
208 [2] H. Sezen and A. Whittaker, "Seismic Performance of Industrial Facilities Affected by

the 1999 Turkey Earthquake," J. Perform. Constr. Facil., no. February, pp. 28-36, 2006.

[3] L. Liberatore, L. Sorrentino, D. Liberatore, and L. Decanini, "Failure of industrial structures induced by the Emilia (Italy) 2012 earthquakes," Eng. Fail. Anal., vol. 34, pp. 629-647, 2013.

[4] G. Magliulo, M. Ercolino, C. Petrone, O. Coppola, and G. Manfredi, "The Emilia Earthquake: Seismic Performance of Precast Reinforced Concrete Buildings," Earthq. Spectra, vol. 30, no. 2, pp. 891-912, Sep. 2013.

[5] D. Bournas, P. Negro, and F. F. Taucer, "Performance of industrial buildings during the Emilia earthquakes in Northern Italy and recommendations for their strengthening," Bull. Earthq. Eng., vol. 12, no. 5, pp. 2383-2404, 2013.

[6] X. Romão et al., "Field observations and interpretation of the structural performance of constructions after the 11 May 2011 Lorca earthquake," Eng. Fail. Anal., vol. 34, 2013.

[7] R. Nascimbene, "Numerical Model of a Reinforced Concrete Building: Earthquake Analysis and Experimental Validation," Period. Polytech. Civ. Eng., vol. 59, no. 4, pp. 521-5D30, 2015.

[8] R. Sacks, C. M. Eastman, and G. Lee, "Parametric 3D modeling in building construction with examples from precast concrete," vol. 13, pp. 291-312, 2004.

[9] F. Clementi, A. Scalbi, and S. Lenci, "Seismic performance of precast reinforced concrete buildings with dowel pin connections," J. Build. Eng., vol. 7, pp. 224-238, 2016.

[10] D. Beilic, C. Casotto, R. Nascimbene, D. Cicola, and D. Rodrigues, "Seismic fragility curves of single story RC precast structures by comparing different Italian codes Seismic fragility curves of single storey RC precast structures by comparing different Italian codes," no. January, 2017.

[11] C. Casotto, V. Silva, H. Crowley, R. Nascimbene, and R. Pinho, "Seismic fragility of Italian RC precast industrial structures," Eng. Struct., vol. 94, pp. 122-136, 2015.

[12] G. Magliulo, G. Fabbrocino, and G. Manfredi, "Seismic assessment of existing precast industrial buildings using static and dynamic nonlinear analyses," Eng. Struct., vol. 30, no. 9, pp. 2580-2588, 2008.

[13] H. M. Elsanadedy, T. H. Almusallam, Y. A. Al-salloum, and H. Abbas, "Investigation of precast RC beam-column assemblies under column-loss scenario," Constr. Build. Mater., vol. 142, pp. 552-571, 2017.

[14] D. Feng, G. Wu, and Y. Lu, "Finite element modelling approach for precast reinforced concrete beam-to-column connections under cyclic loading," Eng. Struct., vol. 174, no. May, pp. 49-66, 2018.

[15] M. Kataoka, M. Ferreira, and A. Debs, "Nonlinear FE analysis of slab-beam-column connection in precast concrete structures," Eng. Struct., vol. 143, pp. 306-315, 2017.

[16] R. Sousa, N. Batalha, and H. Rodrigues, "Numerical simulation of beam-to-column connections in precast reinforced concrete buildings using fibre-based frame models," Eng. Struct. (under Rev).

[17] D. A. Bournas, P. Negro, and F. J. Molina, "Pseudodynamic tests on a full-scale 3-storey precast concrete building: Behavior of the mechanical connections and floor diaphragms," Eng. Struct., vol. 57, pp. 609-627, 2013.

[18] M. Fischinger, B. Zoubek, and T. Isaković, "Seismic Response of Precast Industrial Buildings BT - Perspectives on European Earthquake Engineering and Seismology: Volume 1,” A. Ansal, Ed. Cham: Springer International Publishing, 2014, pp. 131-177.

[19] M. Araújo, L. Macedo, M. Marques, and J. M. Castro, "Code-based record selection methods for seismic performance assessment of buildings," Earthq. Eng. Struct. Dyn., vol. 45, no. 1, pp. 129-148, Jan. 2016. 